\title{
Spermatogonia: stem cells with a great perspective
}

\author{
Sarah Meachem, Viktoria von Schönfeldt and Stefan Schlatt* \\ Institute of Reproductive Medicine of the University Münster, Domagkstr. 11 \\ D-48149 Münster, Germany
}

\begin{abstract}
Interest in spermatogonia has grown in recent years as a result of exciting developments in stem cell research in general and the development of new research tools allowing the isolation, culture and transplantation of these cells. This review focuses on the methodological breakthroughs and highlights the recent findings that have substantially increased understanding of spermatogonial physiology. The article provides a comprehensive overview of the hormonal regulation of spermatogonia and presents several new approaches to the use of spermatogonia in basic science and medicine. In the near future these techniques will allow the development of novel routes for the generation of transgenic lifestock, the treatment of infertility, the targeting for male contraception, and an alternative strategy for fertility preservation of oncological patients.
\end{abstract}

Stem cells are defined in terms of their function. They are self-renewing precursor cells that can generate differentiating cell populations to replenish the loss of cells. Stem cell activity is needed for initiation and maintenance of tissue function (Potten and Loeffler, 1990; van der Kooy and Weiss, 2000; Watt and Hogan, 2000). Stem cells are rare in most systems making it difficult to isolate them and study their function.

Although most stem cells are defined by their ability to produce cell lines belonging to specific lineages, that is haematopoietic (Weissman, 2000) or neuronal stem cells (Gage, 2000), embryonic stem cells are considered to be pluripotent since their progeny can develop into all phenotypes of adult tissues (Vogel, 2000). Only the zygote and the cells produced during the first divisions appear to be totipotent since they also have the ability to form extraembryonic tissues. However, totipotency is maintained in the cells forming the germ line. Early in embryogenesis, a few cells are designated to become primordial germ cells. These cells are recognized through germline-specific transcriptional activity, showing specific expression for the transcription factor Oct 4 (Pesce et al., 1999; Pesce and Scholer, 2000) and the product of the Drosophila gene VASA (Castrillon et al., 2000). Primordial germ cells are also recognized by their expression of alkaline phosphatase. After migration into the undifferentiated gonads, these cells differentiate into female or male germ cell precursors depending on the sexual gonadal differentiation. An

\footnotetext{
*Correspondence

Email: schlats@uni-muenster.de

This review is based on a symposium talk given at the Joint Meeting of the Society for the Study of Fertility, British Fertility Society and British Andrology Society held at the Edinburgh International Conference Centre from 31 July to 2 August 2000.
}

irreversible decision is made when these cells either enter meiosis to become oocytes or when they arrest while seminiferous cord formation is initiated to form a testis. Signalling of these events occurs through somatic cell lineages, forcing the male primordial germ cell to maintain its low differentiation status (Capel, 2000). This mechanism allows the male primordial germ cell to resume proliferative activity at later stages of testicular development, to differentiate into gonocytes and to become a new type of stem cell, the undifferentiated spermatogonium, which gives rise to millions of differentiating germ cells throughout adulthood.

Gonocytes are defined on the basis of morphological characteristics and functional properties, that is, the reinitiation of mitotic activity associated with the formation of the first generation of type A spermatogonia. Spermatogonia are also defined on the basis of their morphology, including the presence of a heterogeneous subset of cells containing undifferentiated (stem cells) and differentiating cells (Meistrich and van Beek, 1993). An excellent description of spermatogonial subtypes and their physiology and a suggestion for a clear nomenclature has been presented by de Rooij and Russell (2000). The number of spermatogonial stem cells is very low: a mouse testis contains about 35000 spermatogonial stem cells (Tegelenbosch and de Rooij, 1993) implying that a rat testis contains about 350000 spermatogonial stem cells (de Rooij and Russell, 2000). At present no specific markers are available for selection of stem cells, and this has limited understanding of their control. Similar limitations restrict study of the different subsets of differentiating spermatogonia.

Despite these limitations, major breakthroughs in understanding of spermatogonial physiology have occurred, primarily due to the development of powerful new tools (Box 1). Spermatogonia are important cells required for the 
Box 1. Some of the technical breakthroughs discussed in this article and their relevance to spermatogonial stem cell research

Technological breakthroughs that have improved understanding of spermatogonial physiology

- Availability of unbiased stereological techniques applicable to quantifying non-spherical particles has led to more sensitive monitoring of spermatogonial number

- Magnetic cell sorting is a fast and effective method for the isolation of c-kit positive spermatogonia from the adult testis

- Spermatogonial surface markers $\left(\alpha_{6}\right.$ and $\beta_{1}$ integrin) have facilitated the enrichment of stem cells

- An in vitro clonogenic method to assay for the proliferation of pure gonocytes in the presence of specific growth factors and testicular underlays

- Germ cell transplantation as a functional assay for stem cell activity

Future perspectives for stem cell research

- Infertility treatment

- Contraceptive strategy

- In vitro spermatogenesis

- Markers for identification of spermatogonial subtypes

- Innovative research using germ cell transplantation

- Preservation of fertility for oncological patients

- Generation of transgenic animals

- Preservation of valuable animals

initiation of spermatogenesis and hence sperm output and the integrity of the male genome relies on their continuous 'error free' proliferation and differentiation. Understanding of spermatogonia has important clinical implications, for example, in the development of contraceptive strategies and fertility treatments in patients with spermatogonial arrest and the protection of spermatogonial stem cells in oncological patients. In the field of animal husbandry, the transfection of spermatogonia may allow the generation of transgenic animals and thus the ability to generate and preserve valuable (for example, rare or breeding stock) animals. In addition, germ cell transplantation techniques, isolation and culture techniques offer novel ways to study spermatogonia that may lead to further breakthroughs in reproductive technology.

This article examines what is known about spermatogonia and the factors that regulate them, detailing the recent technological achievements and the lessons learnt from using them, and discusses the possible future uses for these new approaches in reproductive biology.

\section{Supporters and suppressors: spermatogonial control mechanisms}

Sertoli cells limit the expansion of the spermatogonial population. As testicular size is determined by the number of Sertoli cells present, it is assumed that each Sertoli cell supports a defined number of germ cells and therefore spermatogonia. We hypothesize that Sertoli cells form niches for stem cells and that these niches allow a certain number of stem cells at any particular time to reside in or repopulate the seminiferous tubule. Settlement of stem cells in such a niche was reported by studying somatic cells in the fly ovary (Xie and Spradling, 2000). In addition, the repopulation pattern of spermatogonia after transplantation supports the presence of a germ cell niche (Ohta et al., $2000 a, b)$. The settlement and occupation of these stem cell niches appear to occur autonomously or to depend on genetic programming. Transplanted germ cells from dogs, rabbits and large domestic species are able to repopulate the mouse testis (Dobrinski et al., 1999, 2000), but are not able to differentiate. Hormones do not influence the expansion of stem cells, and the size of the stem cell population is independent of the ability of stem cells to express c-kit or respond to stem cell factor (Ohta et al., 2000a; Fig. 1).

The appearance of differentiating spermatogonia and their expansion are, at least in part, dependent on hormonal cues. Numerous studies using a diverse array of hormonally manipulated in vivo and in vitro models have been used to identify the hormones that stimulate and inhibit the spermatogonial population, as assessed by quantifying the number of spermatogonia using stereological techniques. The availability of unbiased counting methods (Wreford, 1995) paved the way for a more sensitive approach to estimating the spermatogonial population. Flow cytometry has also been used to estimate changes in division and survival of spermatogonia using specific DNA markers. Recolonization of the testis using transplanted germ cells offers an elegant approach to understanding how the testicular microenvironment regulates spermatogonial development. Although numerous factors have been implicated as participating in spermatogonial development, only the major influences are discussed below (Fig. 1).

It is unequivocal that $\mathrm{FSH}$ plays a major role in regulating 


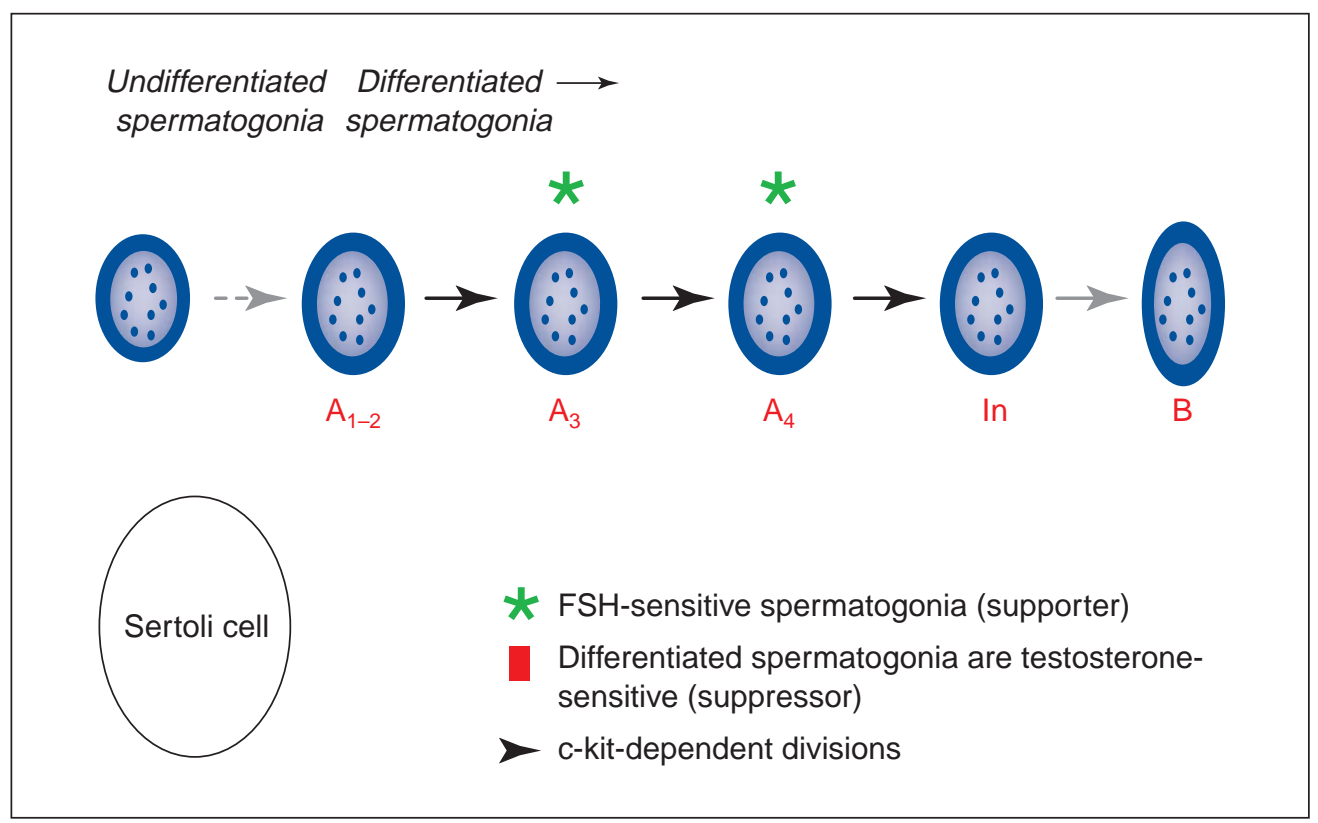

Fig. 1. The testicular stem cell is shown with multiple generations of differentiating spermatogonia in rats and factors known to influence spermatogonial differentiation. The final number of Sertoli cells determines the upper limit for the size of the spermatogonial population. Undifferentiated spermatogonia (stem cells) are regulated autonomously or genetically, depending on the availability of stem cell niches. The appearance and enumeration of differentiated spermatogonia are dependent on the hormonal milieu. Early differentiating spermatogonia are FSH-sensitive. The division of differentiating spermatogonia depends on the stimulation of the c-kit receptor. Since there is no direct evidence for a direct action of FSH on type B spermatogonia, the production of stem cell factor in Sertoli cells might stimulate the divisions of differentiating spermatogonia. Opposite effects are observed for androgens, which suppress the expansion and differentiation of spermatogonia.

adult spermatogonia, as has been shown by restoration and maintenance studies in rat (Chandolia et al., 1991; McLachlan et al., 1995; Sinha Hikim and Swerdloff, 1995; Meachem et al., 1998, 1999; Shennawy et al., 1998) and primate models (Weinbauer et al., 1991; Marshall et al., 1995). The mechanism by which FSH exerts its effect is probably by acting as a survival factor and as a mitogen. The exact site or sites at which FSH influences spermatogonial development are largely unknown. Data obtained after selective withdrawal of FSH by passive immunoneutralization in normal adult rats showed a timedependent decline in the number of early germ cell types, indicating that spermatogonia of types $\mathrm{A}_{3}-\mathrm{A}_{4}$ (associated with stages XIV-I) are the principal sites of FSH action. These stages correspond to the time when the number of FSH receptors (Kangasniemi et al., 1990) and FSH receptor mRNA expression (Heckert and Griswold, 1991) are greatest. FSH-induced cAMP responsivity of Sertoli cells is also greatest at these stages (Parvinen et al., 1980). Depletion of gonadotrophins in primates $(\mathrm{GnRH}$-antagonist treatment for 16 and 25 days) and men receiving androgen- based contraception (for 20 weeks) reduced the number of type B spermatogonia to less than $10 \%$ of controls (Zhengwei et al.,1998a,b), indicating that the spermatogonium is a major target for gonadotrophic stimulation. Whether spermatogonial inhibition is due to the concomitant reduction of $\mathrm{FSH}$ and testosterone remains unknown; however, the data in rats, bonnet monkeys (Aravindan et al., 1993; Moudgal et al., 1997) and rhesus monkeys (Marshall et al., 1995) indicate that it is an effect of FSH withdrawal. The specific site at which spermatogonial development is being inhibited in the monkey and human is not clear. Several studies indicate that A spermatogonia are affected by withdrawal of FSH (Aravindan et al., 1993; Schlatt et al., 1995; Moudgal et al., 1997) and gonadotrophins in monkeys (Schlatt and Weinbauer, 1994). Schlatt and Weinbauer (1994) reported a pronounced inhibition of spermatogonial proliferation (as detected by proliferating cell nuclear antigen, PCNA) after GnRH antagonist administration, indicating that the first step of mitosis (at the A pale spermatogonia) is a site of hormone action. In contrast, Marshall et al. (1995) suggested that B 
spermatogonia rather than A pale spermatogonia were selectively amplified in FSH-treated, hypophysectomized testosterone-replaced rhesus monkeys. However, in rats, there was no evidence for a direct effect of FSH on type B or preleptotene spermatocytes (Meachem et al., 1999).

The role of testosterone in spermatogonial development is unclear. There is no evidence that testosterone supports spermatogonial development in long-term gonadotrophindepleted rats (Meachem et al., 1997, 1998). Meistrich et al. (1994) provided compelling evidence that high testicular testosterone concentrations are detrimental to spermatogonial development and suppression of testosterone concentrations is required to promote spermatogonial development in the irradiated rat and the juvenile spermatogonial depletion (jsd) mutant mouse models (Matsumiya et al., 1999). In agreement with these findings, the efficiency for donor spermatogonia to colonize a recipient testis was enhanced by $\mathrm{GnRH}$ antagonist treatment in transplantation studies, and only a transient reduction in testosterone was required (Ogawa et al., 1999a).

Stem cell factor (SCF) and its receptor c-kit play an important role in spermatogonial development. Mutations in the gene encoding either SCF or c-kit results in infertility owing to defective migration, proliferation and survival of primordial spermatogonia. Disruption of SCF action prevents spermatogonia from undergoing mitosis. Elegant studies in which adult mice were injected with anti c-kit antibodies caused the depletion of all differentiating types of spermatogonia, demonstrating that this population is c-kit-dependent in contrast to the c-kit-independent, undifferentiated spermatogonia (Yoshinaga et al., 1991). SCF has been found to act as a mitogen (Rossi et al., 1993; Allard et al., 1996) and survival factor (Dirami et al., 1999; Packer et al., 1995). The important role of the SCF-c-kit system has been substantiated by transplantation of spermatogonia from infertile mice carrying a mutation of the SCF gene into infertile mice with a mutated c-kit receptor gene. The presence of Sertoli cells producing membrane-bound SCF and germ cells expressing the functional c-kit receptor leads to qualitatively normal repopulation of the testes with developing germ cells (Ogawa et al., 2000). Inhibin inhibits the incorporation of tritiated thymidine into differentiated mice and hamster spermatogonia (van Dissel-Emiliiani et al., 1989) whereas activin stimulates spermatogonial mitosis in vitro (Mather et al., 1990). Genetic studies indicate that the bcl-2 family plays a key role in integrating the positive and negative signals on spermatogonial survival with certain members promoting cell survival (for example, Bcl-2, BCL- $\mathrm{x}_{\mathrm{L}}, \mathrm{BCl}-\mathrm{w}$ and A1/Bfl-1) and others promoting cell death (for example, Bax, Bak, Bad and Bim) (Adams and Cory, 1998). For example, inactivation of pro-apoptotic bax or the transgene of anti-apoptotic bcl-2 or bcl- $x_{L}$ in germ cells results in the accumulation of pre-meiotic cells, a failure of the first spermatogenic wave and absence of adult spermatogenesis. Transgenic loss of the Sertoli cell-produced glial cell linederived neurotrophic factor (GDNF) function results in depletion of stem cell reserves, whereas mice overexpressing GDNF accumulate undifferentiated spermatogonia (Meng et al., 2000). Whether these factors affect spermatogonia directly or are intermediates in the gonadotrophin response remains unclear, although a complex set of co-ordinated interactions between hormones and cytokines is most likely required to establish and sustain optimal spermatogonial development.

\section{Away from home: spermatogonia in culture}

The establishment of a good culture system to study spermatogonia has been hampered by technical difficulties in isolating defined subsets of spermatogonia. Before 1990, a number of investigators (Bellvé et al., 1977; Bucci et al., 1986) described procedures to isolate spermatogonia from immature mice, but research on spermatogonia did not progress far mainly because there were no adequate markers that could establish conclusively the identity of spermatogonia after isolation. This problem was partially solved when it was recognized that the c-kit receptor could be used to identify differentiating type A spermatogonia (Dym et al., 1995; Schrans-Stassen et al., 1999). Success in isolating spermatogonia has led to a functional assay (transplantation technique) to study spermatogonia physiology, which will be discussed in detail. This section details the recent isolation and culture methods being used and the lessons that have been learnt along the way.

Obtaining a pure culture of spermatogonia is considered difficult owing to problems associated with a small subset of cells. Isolation of type A spermatogonia was achieved with a purity of greater than $95 \%$ by sedimentation velocity at unit gravity (Dirami et al., 1996). As this isolation technique selects cells on the basis of their size and shape, it can only be applied to immature animals in which the number of other germ cells is small and presents a specific feature of spermatogonia. Isolation of adult spermatogonia is more difficult than isolation from immature testes primarily because of the presence of many germ cells with similar features (the spermatogonial population accounts for $<4 \%$ of all spermatogenic cells). Nonetheless, a procedure for the isolation of adult spermatogonia has been described for vitamin A-deficient adult rats using a Percoll gradient and enrichment by pre-plating on peanut agglutinin and separating on a Percoll gradient (Van Pelt et al., 1996). Magnetic cell sorting is a fast and effective method for the isolation of spermatogonia from testicular cell suspension of various species using c-kit antibodies to detect the receptor in the membrane of spermatogonia (von Schönfeldt et al., 1999). The advantage of this technique over elutriation methods is that it can be used for the isolation of spermatogonia from adult testes since the isolation efficiency depends on the efficient binding of the antibody and is therefore not hampered by the presence of other germ cell types of similar shape and size. The c-kit antibody can be used as a marker to enrich differentiating spermatogonia, but probably not the 'true' stem cell. 
However, the description of new markers (that is, $\alpha_{6}$ and $\beta_{1}$ integrin; Shinohara et al., 1999) enables the selective enrichment of stem cells and other spermatogonial subtypes. Combining negative and positive selection strategies for spermatogonia provides a promising tool for future research.

Initiation of spermatogonial proliferation has been observed in organ culture (Boitani et al., 1993; Schlatt et al., 1999a; Meehan et al., 2000). Progression of spermatogonia into meiosis has been observed in seminiferous tubule fragments (Parvinen et al., 1983) but not in cell (Hasthorpe et al., 1999) and co-cultures (Tres and Kierszenbaum, 1983; Hadley et al., 1985). Maturation from stem cells to the beginning of meiotic prophase has not been achieved in vitro and thus the relevance of studies in vitro to events in vivo has been questioned. It appears that both the initiation of spermatogonial differentiation from stem cells and the entry of differentiating spermatogonia into meiosis is blocked in cultured cells, even though spermatogonial stem cells are maintained after several months of culture and their transplantation re-initiates spermatogenesis (Nagano et al., 1998). However, cultures of differentiating spermatogonia allow the study of certain factors and mechanisms of spermatogonial survival that promote clonal outgrowth and induction of apoptosis. Whether the passage of spermatogonia into meiosis (and hence cell migration through the seminiferous epithelium) depends on the structural support of the seminiferous epithelium, signalling through intercellular matrix or the availability of specific factors in the testicular microenvironment that modulate this event is, thus far, unknown. As yet, organ and tubule culture are the only tools for studying the factors and mechanisms involved in full pre-meiotic germ cell development until meiotic progression of cells.

A 'clonogenic' method to assay for the proliferation of gonocytes in vitro has been described by Hasthorpe et al. (1999, 2000). In brief, a mouse gonocyte is plated in a collagen IV-coated microtitre well containing Iscoves modified Dulbecco's medium and 20\% FCS for 4-5 days. The gonocyte-derived colonies consist of 4 to $>256$ cells per colony, which may enable certain spermatogonial subtypes to be collected, rendering purity and identification issues of spermatogonial subtypes things of the past. Results from the two studies show that testicular cell underlays inhibit gonocyte-derived growth, indicating that the hormonal milieu of the testis may act to suppress early germ cell development (Hasthorpe et al., 2000). This finding is consistent with other studies that report no proliferation effects of gonocytes in Sertoli cell co-cultures (Orth and Boehm, 1990; de Miguel et al., 1996). This novel method may become a powerful tool in understanding the control mechanisms of and developing markers specific to the various spermatogonial subtypes.

The availability of isolation and culture techniques will undoubtedly pave the way for innovative research into stem cell biology, leading to further breakthroughs in understanding of spermatogonial physiology and the development of powerful tools.

\section{A leap forward: germ cell transplantation}

The first successful description of germ cell transplantation in mice was presented by Brinster and Zimmermann (1994) and Brinster and Avarbock (1994). Donor spermatogenesis, recognized by developing germ cells carrying the lac- $Z$ gene, was restored from spermatogonial stem cells microinjected into the seminiferous tubules of host animals (Brinster and Zimmermann, 1994; Fig. 2). Some mice were mated and the transmission of the germ cell donor haplotype was proven in the offspring (Brinster and Avarbock, 1994; Ogawa et al., 2000). Later studies showed that most transplanted cells degenerate and disappear from the testis before the first meiotic donor germ cells appear after 1 month (Parreira et al., 1998). As an alternative to intratubular infusion of germ cells by microinjection, injections into the efferent ducts as well as into the rete testis of the host mice have been used effectively (Ogawa et al., 1997; Fig. 2). Xenogeneic transfer of rat germ cells into mouse testis prompted rat germ cells to associate with mouse Sertoli cells (Clouthier et al., 1996) and vice versa (Ogawa et al., 1999b). The differentiation of rat germ cells in mouse testes occurred according to the kinetics and topography typical for rats (Franca et al., 1998). Transplanted spermatogonia from hamsters, rabbits, dogs and large domestic species were not able to restore spermatogenesis fully in the immunodeficient mouse testis (Ogawa et al., 1999a; Dobrinski et al., 1999, 2000). The hamster-tomouse transfer resulted in the production of abnormal hamster spermatozoa. Rabbit or dog spermatogonia repopulated the basal compartment of the host seminiferous tubules but were unable to undergo differentiation.

Some lessons have already been learnt from germ cell transplantation experiments: (i) the blood-testis barrier did not hinder the migration of stem spermatogonia from the adluminal to the basal compartment of the seminiferous epithelium, indicating that the mechanism for stem cell recognition persists in the adult testis; (ii) the absence of c-kit allows stem cell growth but blocks differentiation of germ cells (Ogawa et al., 2000). The important role of the c-kit-SCF system was further substantiated by repeated transplantation of green fluorescent protein (GFP)-positive spermatogonia into testes from stem cell-deficient mutant mice and back into wild-type strains (Ohta et al., 2000a). Furthermore, the growth pattern of fluorescent spermatogonia indicates the existence of stem cell niches.

Many new approaches have been developed to improve transplantation technology and have led to significant advancements in understanding of spermatogonial stem cell biology. Successful cryopreservation of donor germ cells for long periods before the transfer has been established (Avarbock et al., 1996, Nagano and Brinster, 1998) as well as transplantation of cultured spermatogonial stem cells (Nagano et al., 1998). Sorting of germ cells before the transfer has allowed the characterization of marker genes on spermatogonial stem cells and an improvement in transplantation efficiency (Shinohara et al., 1999). Further 


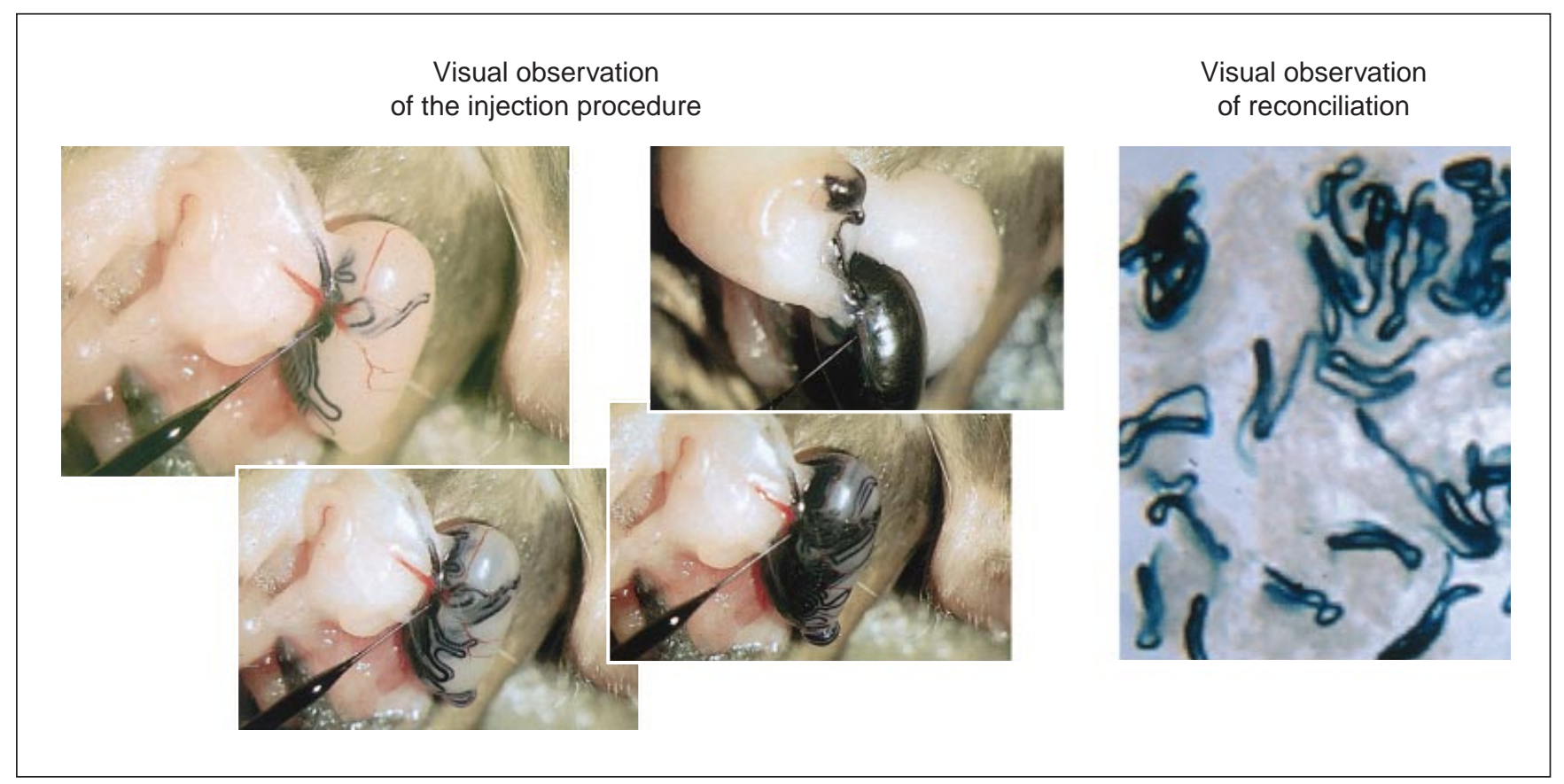

Fig. 2. Transfer of donor cells into the host testis, performed by infusion of the germ cell suspension into the rete testis using a glass needle. The addition of Trypan blue allows the visual control of the infusion process. Usually, complete filling of the testis is achieved after a few minutes. Repopulation is tested 3 months after germ cell transfer. Two strains of mice are used for germ cell transplantation. The first strain serves as a donor for testicular stem cells. This mouse is a carrier of a transgene (the most commonly used is the $L a c-Z$ transgene, which can be detected in tissue sections by staining with X-gal). The host animal is a germ cell-deficient mouse as a result of cytotoxic treatment using busulfan or a gene mutation. The right-hand photograph shows a squash preparation of testicular tissue after X-gal staining. The blue colour indicates seminiferous tubules repopulated by donor cells. (This photograph was kindly donated by Ina Dobrinski, Pennsylvania University, Center for Animal Transgenesis and Germ Cell Research, Kennett Square, USA.)

improvement was achieved by hormone withdrawal through $\mathrm{GnRH}$-agonist treatment of the hosts (Ogawa et al., 1999a).

Germ cell transplantation has become an assay to estimate the potential of germ cell development and the site of action in transgenic animals with disturbed fertility (Fig. 3 ). As described above, the importance of c-kit expression of spermatogonia and SCF expression of Sertoli cells has been demonstrated in transplantation studies. Mahato et al. (2000) transplanted oestrogen receptor $\alpha$-deficient germ cells into wild-type testes, and showed that the mutated germ cells induced qualitatively normal spermatogenesis. In contrast, after transplantation of germ cells from mice carrying the $j s d$ mutation, no donor-derived spermatogenesis can be established (Boettger-Tong et al., 2000). The use of GFPpositive spermatogonia allows for the real-time observation of transplanted cell clones and opens new pathways for the detailed study of stem cell colonization and germ cell development (Ohta et al., 2000b).

\section{Spermatogonial transplantation: hope for tumour patients}

Oncological diseases such as testicular cancer, leukaemia and Hodgkin disease occur in childhood with an incidence of 1 in 581 children up to 15 years of age (Stiller et al., 1995). Improved diagnostics, surgery, radiation and chemotherapy have led to an increase in the survival rate of these patients. However, many male patients have to face temporary or even permanent sterility caused by the oncological treatment regimen (Naysmith et al., 1998). The rapidly dividing diploid spermatogonia are the most sensitive testicular cells to the cytotoxic effects of radiotherapy (Meistrich, 1993) and chemotherapy (Meistrich et al., 1982). Unfortunately, all hormonal attempts to protect the seminiferous epithelium by reducing the rate of spermatogenesis have failed and an improvement in post-treatment fertility has not yet been demonstrated (Waxman et al., 1987; Meistrich et al., 1994). Therefore, new strategies for better fertility protection are needed for oncological patients (Meirow and Schenker, 1995). Germ cell transplantation is considered a potential tool for fertility preservation in oncological patients (Aslam et al., 2000; Schlatt et al., 2000; Fig. 4). Although this approach has yet to be optimized and the efficiency and safety of germ cell transplantation as a clinical application has to be demonstrated, several significant initial problems have been solved. A transfer technique into primate testes has been developed (Schlatt et al., 1999b) and used to perform the 


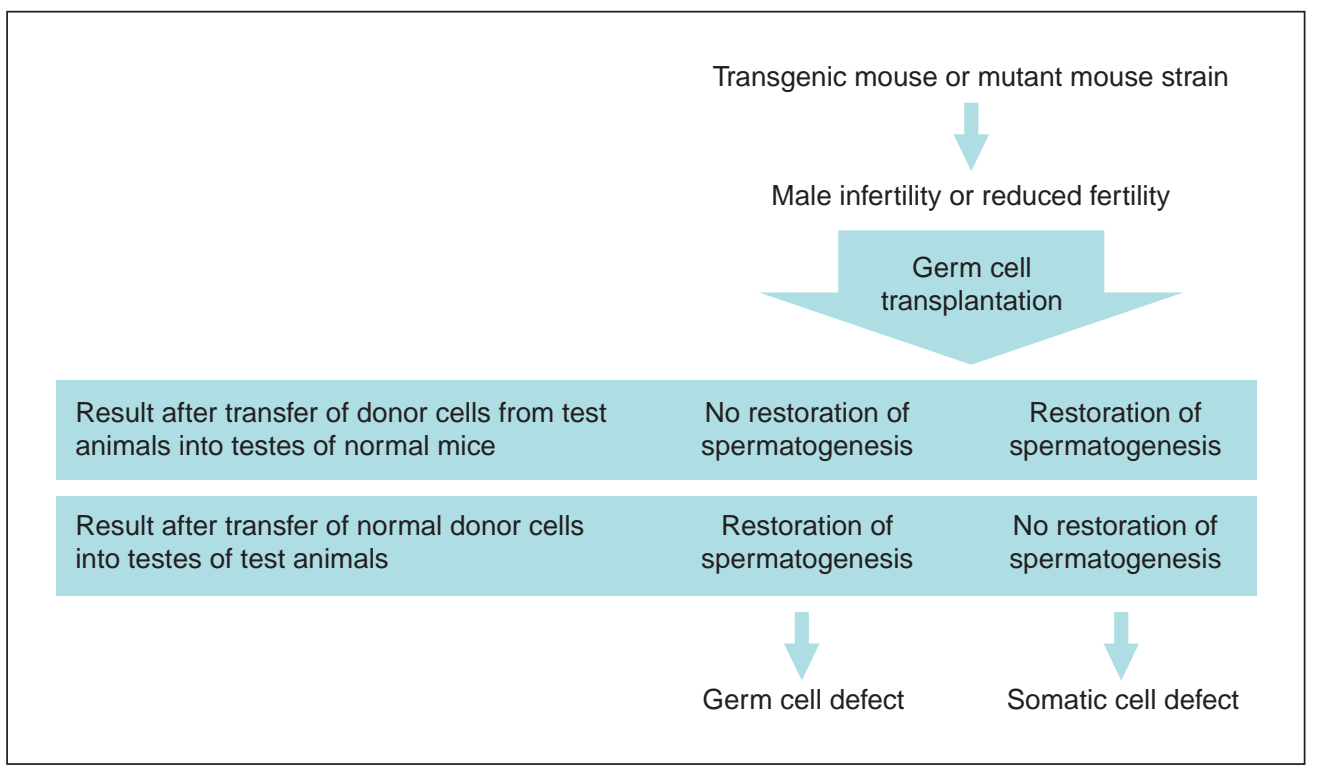

Fig. 3. Illustration of how germ cell transplantation can be applied to determine the cause of infertility or subfertility in mutant or transgenic mouse strains. The generation and discovery of many different mouse lines carrying specific transgenes or knockouts of specific target genes has become an important tool for the determination of gene function. The analysis of genes responsible for spermatogenesis and testis function is difficult since it is often impossible to determine whether the observed defect is due to a disturbance in the germ line or the somatic component of the testis. Germ cell transplantation is a tool for the determination of the cellular target in transgenic animals showing male infertility. The degree of spermatogenic recovery indicates whether the somatic environment (that is, transfer of wild-type germ cells into transgenic testes) or the germ line (that is, transfer of transgenic germ cells into wild-type testes) is responsible for the disturbance in spermatogenesis and at which stage of germ cell development the defect occurs. Therefore, germ cell transplantation is already an important tool for the screening of genes responsible for germ cell maturation and testis function.

first clinical trial in oncological patients (Radford et al., 1999). The easiest, least invasive and most efficient filling of the testis was obtained by injections into the rete testis, with the placement of the injection needle into the rete testis controlled by ultrasonography (Schlatt et al., 1999b).

Extracorporal storage of the male germ line cells is an important part of the treatment. Various useful options should be explored: (i) cryopreservation of testicular tissue or cell suspensions; (ii) long-term cell or organotypic culture; and (iii) transplantation of cells or grafts into host animals. The final approach should allow a good survival rate of testicular stem cells and exclude genetic damage of the genome.

Safety and efficiency are important aspects of spermatogonial transplantation. Reintroduction of malignant cells into a patient who was previously cured of the disease must be excluded. Before the transfer, a selection of spermatogonia or an elimination of malignant cells might be performed. Magnetic cell sorting with specific antibodies for spermatogonial surface antigens can be used for the enrichment of spermatogonia from testicular cell suspensions (von Schönfeldt et al., 1999).

Spermatogonial transplantation offers the prospect of fertility preservation in oncological patients. However, more research has to be performed to resolve clinical issues related to the efficiency and safety of the approach. In addition, the discussion on legal and ethical issues raised has to proceed and controlled clinical trials completed before widespread implementation of this approach can occur.

\section{Spermatogonial manipulation: a must for generation and preservation of breeding stock}

Germ cell transplantation may have important implications for the preservation of valuable animals, for example, rare animals and important livestock. Cryopreservation of testicular stem cells offers the chance of long-term storage of the male germ line (Avarbock et al., 1996; Nagano and Brinster, 1998). Transfection and selection of cultivated spermatogonia would allow insertion of transgenes into the male germ line via transplantation. In principle, this technique appears easier than the transfection and selection of embryonic stem cells. Many more species could be used for production of transgenes as (in vitro-transfectable) embryonic stem cells can only be obtained from a few 


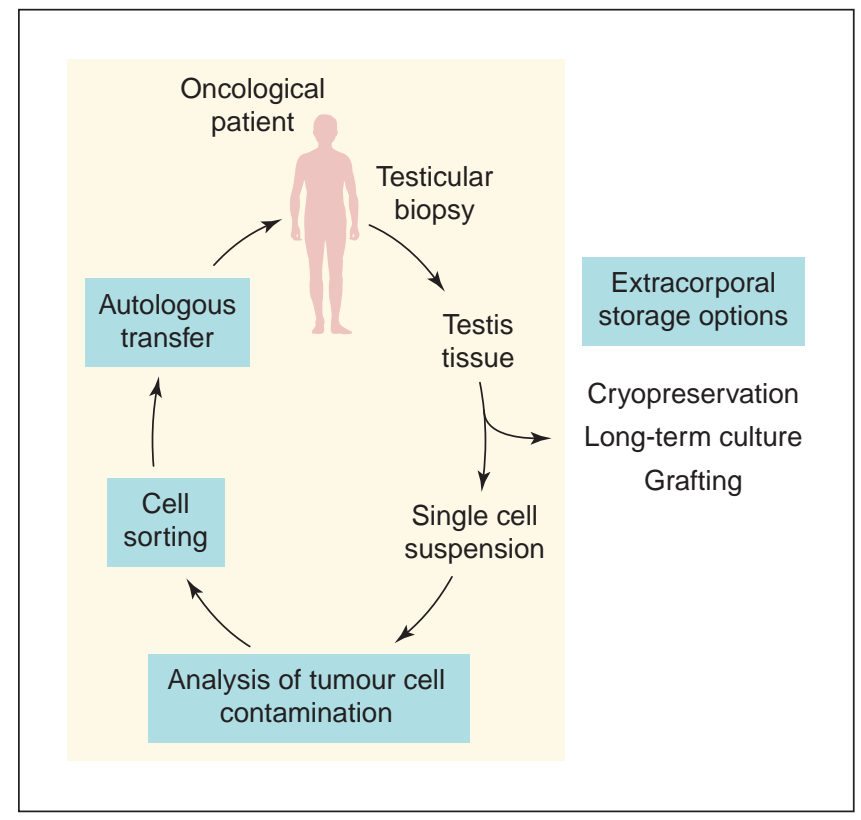

Fig. 4. Illustration of potential fertility preservation by germ cell retrieval, storage and transplantation of testicular stem cells. Irradiation and chemotherapy destroy the entire population of highly sensitive differentiating spermatogonia. Furthermore, they can induce DNA damage in the stem cell population. Depending on the intensity of radiation or cytotoxic treatment, as well as on the individual response, temporary or permanent infertility is observed in most oncological patients after therapy. Retrieval of testicular stem cells by biopsy and extracorporal storage by cryopreservation, long-term culture or grafting protects the germ cells from the devastating effects of the therapy. After recovery from the disease, autologous transfer of these cells into the seminiferous tubules might induce restoration of spermatogenesis. Assays and cell sorting techniques must be developed to minimize the risk of transferring malignant cells back into the patient.

mouse strains, whereas spermatogonia are present in all mammalian species. First attempts using retrovirusmediated gene delivery have been performed and resulted in the successful transfer of a reporter gene into mouse spermatogonial stem cells and testis which persisted for more than 6 months (Nagano et al., 2000). The availability of such a technique presents a valuable tool for use in the creation of transgenic livestock that will undoubtedly have a major impact on the field of veterinary science.

This review was made possible through funding of the Wellcome Trust (UK) in the form of a Postdoctoral Research Fellowship in Population Studies awarded to Sarah Meachem. The work reported in this review was supported by the Deutsche Forschungsgemeinschaft (DFG Ni 130/17). The authors are indebted to E. Nieschlag, G. F. Weinbauer, R. Gosden, C. Rolf, A. Kamischke, G. Rosiepen, P. F. Brook, A. G. Schepers, L. Foppiani and I. Upmann, who contributed to the work presented.

\section{References}

Key references are identified by asterisks.

Adams JM and Cory S (1998) The Bcl-2 family: arbiters of cell survival Science 281 1322-1326

Allard EK, Blanchard KT and Bockelheide K (1996) Exogenous stem cell factor (SCF) compensates for altered endogenous SCF expression in 2,5hexanedione-induced testicular atrophy in rats Biology of Reproduction 55 185-193

Aravindan GR, Gopalakrishnan K, Ravindranath N and Moudgal NR (1993) Effect of altering endogenous gonadotrophin concentrations on the kinetics of testicular germ cell turnover in the bonnet monkey (Macaca radiata) Journal of Endocrinology 137 485-495

Aslam I, Fishel S, Moore H, Dowell K and Thornton S (2000) Fertility preservation of boys undergoing anti-cancer therapy: a review of the existing situation and prospects for the future Human Reproduction $\mathbf{1 5}$ 2154-2159

Avarbock MR, Brinster CJ and Brinster RL (1996) Reconstitution of spermatogensis from frozen spermatogonial stem cells Nature Medicine 2 693-696

Bellvé AR, Cavicchia JC, Millette O'Brien DA, Bhatnagar YM and Dym M (1977) Spermatogenic cells of the prepuberal mouse: isolation and morphological characterization Journal of Cell Biology 74 68-85

Boettger-Tong HL, Johnston DS, Russell LD, Griswold MD and Bishop CE (2000) Juvenile spermatogonia depletion (jsd) mutant seminiferous tubules are capable of supporting transplanted spermatogenesis Biology of Reproduction 63 1185-1191

Boitani C, Politi MG and Menna T (1993) Spermatogonial cell proliferation in organ culture of immature rat testis Biology of Reproduction $\mathbf{4 8}$ 761-767

Brinster RL and Avarbock MR (1994) Germline transmission of donor haplotype following spermatogonial transplantation Proceedings National Academy of Sciences USA $9111303-11307$

*Brinster RL and Zimmermann JW (1994) Spermatogenesis following male germ-cell transplantation Proceedings National Academy of Sciences USA $9111289-11302$

Bucci LR, Brock WA, Johnson TS and Meistrich ML (1986) Isolation and biochemical studies of enriched populations of spermatogonia and early spermatocytes from rat testes Biology of Reproduction 34 195-206

Capel B (2000) The battle of the sexes Mechanisms of Development 92 89-103

Castrillon DH, Quade BJ, Wang TY, Quigley C and Crum CP (2000) The human VASA gene is specifically expressed in the germ cell lineage Proceedings National Academy of Sciences USA 97 9585-9590

Chandolia RK, Weinbauer GF, Fingscheidt U, Bartlett JM and Nieschlag E (1991) Effects of flutamide on testicular involution induced by an antagonist of gonadotrophin-releasing hormone and on stimulation of spermatogenesis by follicle-stimulating hormone in rats Journal of Reproduction and Fertility 93 313-323

Clouthier DE, Avarbock MR, Maika SD, Hammer RE and Brinster RL (1996) Rat spermatogenesis in mouse testis Nature 381 418-421

de Miguel MP, De Boer-Brouwer M, Paniagua R, van den Hurk R, de Rooij DG and Van Dissel-Emiliani FM (1996) Leukemia inhibitory factor and ciliary neurotropic factor promote the survival of Sertoli cells and gonocytes in coculture system Endocrinology 137 1885-1893

de Rooij DG and Russell LD (2000) All you wanted to know about spermatogonia but were afraid to ask Journal of Andrology 21 776-798

Dirami G, Ravindranath N, Jia MC and Dym M (1996) Isolation and culture of immature rat type A spermatogonial stem cells in signal transduction in testicular cells. In Basic and Clinical Aspects pp 141-165 Ernst Schering Research Foundation Workshop, Supplement 2, Eds FO Hansson, K Levy and V Tasken. Springer-Verlag, Berlin

Dirami G, Ravindranath N, Pursel V and Dym M (1999) Effects of stem cell factor and granulocyte macrophage-colony stimulating factor on survival of porcine type A spermatogonia cultured in KSOM Biology of Reproduction $61225-230$

Dobrinski I, Avarbock MR and Brinster RL (1999) Transplantation of germ cells from rabbits and dogs into mouse testes Biology of Reproduction 61 1331-1339 
Dobrinski I, Avarbock MR and Brinster RL (2000) Germ cell transplantation from large domestic animals into mouse testes Molecular Reproduction and Development $\mathbf{5 7} 270-279$

Dym M, Jia M-C, Dirami G, Price JM, Rabin SJ, Mocchetti I and Ravindranath $\mathbf{N}$ (1995) Expression of the c-kit receptor and its autophosphorylation in immature rat type A-spermatogonia Biology of Reproduction 52 8-19

Franca LR, Ogawa T, Avarbock MR, Brinster RL and Russell LD (1998) Germ cell genotype controls cell cycle during spermatogenesis in the rat Biology of Reproduction 59 1371-1377

Gage FH (2000) Mammalian neural stem cells Science 287 1433-1438

Hadley MA, Byers SW, Suarez-Quian CA, Kleinman HK and Dym M (1985) Extracellular matrix regulates Sertoli cell differentiation, testicular cord formation, and germ cell development in vitro. Journal of Cell Biology 101 1511-1522

*Hasthorpe S, Barbic S, Farmer PJ and Hutson JM (1999) Neonatal mouse gonocyte proliferation assayed by an in vitro clonogenic method Journal of Reproduction and Fertility 116 335-344

Hasthorpe S, Barbic S, Farmer PJ and Hutson JM (2000) Growth factor and somatic cell regulation of mouse gonocyte-derived colony formation in vitro. Journal of Reproduction and Fertility 119 85-91

Heckert LL and Griswold MD (1991) Expression of follicle-stimulating hormone receptor mRNA in rat testes and Sertoli cells Molecular Endocrinology 5 670-677

Kangasniemi M, Kaipia A, Toppari J, Perheentupa A, Huhtaniemi I and Parvinen M (1990) Cellular regulation of FSH binding in rat seminiferous tubules Journal of Andrology 11 336-343

McLachlan RI, Wreford NG, De Kretser DM and Robertson DM (1995) The effects of recombinant follicle-stimulating hormone on the restoration of spermatogenesis in the gonadotropin-releasing hormone-immunized adult rat Endocrinology 136 4035-4043

Mahato D, Goulding EH, Korach KS and Eddy EM (2000) Spermatogenic cells do not require estrogen receptor-alpha for development or function Endocrinology 141 1273-1276

Marshall GR, Zorub DS and Plant TM (1995) Follicle-stimulating hormone amplifies the population of differentiated spermatogonia in the hypophysectomised testosterone-replaced adult Rhesus monkey (Macaca mulatta) Endocrinology 136 3504-3511

Mather JP, Attie KM, Woodruff TK, Rice GC and Phillips DM (1990) Activin stimulates spermatogonial proliferation in germ-Sertoli cell cocultures from immature rat testis Endocrinology 127 3206-3214

Matsumiya K, Meistrich ML, Shetty G, Dohmae K, Tohida A, Okuyama A and Nishimune $\mathbf{Y}$ (1999) Stimulation of spermatogonial differentiation in juvenile spermatogonial depletion (jsd) mutant mice by gonadotropinreleasing hormone antagonist Endocrinology 140 4912-4915

Meachem SJ, Wreford NG, Roberston DM and McLachlan RI (1997) Androgen action on the restoration of spermatogenesis in adult rats: effects of human chorionic gonadotrophin, testosterone and flutamide administration on germ cell number International Journal of Andrology 20 70-79

Meachem SJ, Wreford NG, Stanton PG, Robertson DM and McLachlan RI (1998) FSH is important for the initial phase of spermatogenic restoration in adult rats following gonadotrophin suppression Journal of Andrology $19725-735$

*Meachem SJ, McLachlan RI, Stanton PG, Robertson DM and Wreford NG (1999) FSH immunoneutralisation acutely impairs spermatogonial development in normal adult rats Journal of Andrology 20 756-762

Meehan T, Schlatt S, O'Bryan MK, deKretser DM and Loveland KL (2000) Regulation of germ cell and Sertoli cell development by activin, follistatin, and FSH Developmental Biology 220 225-237

Meirow D and Schenker JD (1995) Cancer and male infertility Human Reproduction 10 2017-2022

Meistrich ML (1993) Effects of chemotherapy and radiotherapy on spermatogenesis European Urology 23 136-141

Meistrich ML and van Beek MEAB (1993) Spermatogonial stem cells. In Cell and Molecular Biology of the Testis pp 266-295 Eds C Desjardins and LL Ewing LL. Oxford University Press, New York

Meistrich ML, Finch M, da Cunha MF, Hacker U and Au WW (1982) Damaging effects of fourteen chemotherapeutic drugs on mouse testis Cancer Research 42 122-131
Meistrich ML, Wilson G, Ye W-S, Kurdoglu B, Parchuri N and Terry N (1994) Hormonal protection from procarbazine-induced testicular damage is selective for survival and recovery of stem spermatogonia Cancer Research 54 1027-1034

Meng X, Hyvonen ME, Parvinen M et al. (2000) Regulation of cell fate decision of undifferentiated spermatogonia by GDNF Science 287 1489-1493

Moudgal NR, Sairam NR, Krishnamurthy HN, Sridhar S, Krishnamurthy H and Khan H (1997) Immunization of male bonnet monkeys (M. radiata) with a recombinant FSH receptor preparation affects testicular function and fertility Endocrinology 138 3065-3068

Nagano M and Brinster RL (1998) Spermatogonial transplantation and reconstitution of donor cell spermatogenesis in recipient males Acta Pathology Microscopy and Immunology Scandinavia 106 47-55

Nagano M, Avarbock MR, Leonida EB, Brinster CJ and Brinster RL (1998) Culture of mouse spermatogonial stem cells Tissue and Cell 30 389-397

Nagano M, Shinohara T, Avarbock MR and Brinster RL (2000) Retrovirusmediated gene delivery into male germ line stem cells FEBS Letters $\mathbf{4 7 5}$ 7-10

Naysmith TE, Blake DA, Harvey VJ and Johnson NP (1998) Do men undergoing sterilizing cancer treatments have a fertile future? Human Reproduction 13 3250-3255

Ogawa T, Arechaga JM, Avarbock MR and Brinster RL (1997) Transplantation of testis germinal cells into mouse seminiferous tubules International Journal of Developmental Biology 41 111-122

Ogawa T, Dobrinski I and Brinster RL (1999a) Recipient preparation is critical for spermatogonial transplantation in the rat Tissue and Cell 31 $461-472$

Ogawa T, Dobrinski I, Avarbock MR and Brinster RL (1999b) Xenogeneic spermatogenesis following transplantation of hamster germ cells to mouse testes Biology of Reproduction 60 515-521

Ogawa T, Dobrinski I, Avarbock MR and Brinster RL (2000) Transplantation of male germ line stem cells restores fertility in infertile mice Nature Medicine 6 29-34

Ohta H, Yomogida K, Dohmae K and Nishimune Y (2000a) Regulation of proliferation and differentiation in spermatogonial stem cells: the role of c-kit and its ligand SCF Development 127 2125-2131

Ohta H, Yomogida K, Yamada S, Okabe M and Nishimune Y (2000b) Realtime observation of transplanted 'green germ cells': proliferation and differentiation of stem cells Development Growth and Differentaition 42 105-112

Orth JM and Boehm R (1990) Functional coupling of neonatal rat Sertoli cells and gonocytes in coculture Endocrinology 127 2812-2820

Packer AI, Besmer P and Bachvarova RF (1995) Kit ligand mediates survival of type A spermatogonia and dividing spermatocytes in the mouse testis Molecular Reproduction and Development 42 303-310

Parreira CG, Ogawa T, Avarbock MR, Franca LR, Brinster RL and Russell LD (1998) Development of germ cell transplants in mice Biology of Reproduction 59 1360-1370

Parvinen M, Marana R, Robertson DM, Hansson V and Ritszen EM (1980) Functional cycle of rat Sertoli cells: differential binding and action of follicle-stimulating hormone at various stages of the spermatogenic cycle. In Testicular Development, Structure and Function pp 425-432 Eds A Steinberger and E Steinberger. Raven Press, New York

Parvinen M, Wright WW, Phillips DM, Mather JP, Musto NA and Bardin CW (1983) Spermatogenesis in vitro: completion of meiosis and early spermiogenesis Endocrinology 112 1150-1152

Pesce M and Scholer HR (2000) Oct-4: control of totipotency and germline determination Molecular Reproduction and Development 55 452-457

Pesce M, Anastassiadis K and Scholer HR (1999) Oct-4: lessons of totipotency from embryonic stem cells Cells Tissues and Organs 165 144-152

Potten CS and Loeffler M (1990) Stem cells: attributes, cycles, spirals, pitfalls and uncertainties. Lessons for and from the crypt Development $\mathbf{1 1 0}$ 1001-1020

Radford JA, Shalet SM and Lieberman BA (1999) Fertility after treatment for cancer British Medical Journal 319 935-936

Rossi P, Dolci S, Albanesi C, Grimaldi P, Ricca R and Geremia R (1993) Follicle-stimulating hormone induction of steel factor (SLF) mRNA in mouse Sertoli cells and stimulation of DNA synthesis in spermatogonia by soluble SLF Developmental Biology 155 68-74 
Schlatt S and Weinbauer GF (1994) Immunohistochemical localization of proliferating cell nuclear antigen as a tool to study cell proliferation in rodent and primate testes International Journal of Andrology 17 214-222

Schlatt S, Arslan M, Weinbauer GF, Behre HM and Nieschlag E (1995) Endocrine control of testicular somatic and premeiotic germ cell development in the immature testis of the primate Macaca mulatta. European Journal of Endocrinology 133 235-247

Schlatt S, Zhengwei Y, Meehan T, deKretser DM and Loveland KL (1999a) Application of morphometric techniques to postnatal rat testes in organ culture: insights into testis growth Cell and Tissue Research 298 335-343

*Schlatt S, Rosiepen G, Weinbauer GF, Rolf C, Brook PF and Nieschlag E (1999b) Germ cell transfer into rat, bovine, monkey and human testes Human Reproduction 14 144-150

Schlatt S, von Schönfeldt V and Schepers AG (2000) Male germ cell transplantation: an experimental approach with a clinical perspective British Medical Bulletin 56 824-836

Schrans-Stassen BH, van de Kant HJ, de Rooij DG and van Pelt AM (1999) Differential expression of c-kit in mouse undifferentiated and differentiating type A spermatogonia Endocrinology 140 5894-5900

Shennawy El, Gates RJ and Russell LD (1998) Hormonal regulation of spermatogenesis in the hypophysectomized rat: cell viability after hormonal replacement in adults after intermediate periods of hypophysectomy Journal of Andrology 19 320-334

Shinohara T, Avarbock MR and Brinster RL (1999) Beta 1- and alpha 6integrin are surface markers on mouse spermatogonial stem cells Proceedings National Academy of Sciences USA 96 5504-5509

Sinha Hikim AP and Swerdloff RS (1995) Temporal and stage-specific effects of recombinant human follicle-stimulating hormone on the maintenance of spermatogenesis in gonadotropin-releasing hormone antagonist-treated rat Endocrinology 136 253-261

Stiller CA, Allen MB and Eatock EM (1995) Childhood cancer in Britain: the National Registry of Childhood Tumours and incidence rates 1978-1987 European Journal of Cancer 31A 2028-2034

Tegelenbosch RA and de Rooij DG (1993) A quantitative study of spermatogonial multiplication and stem cell renewal in the $\mathrm{C} 3 \mathrm{H} / 101 \mathrm{~F}_{1}$ hybrid mouse Mutation Research 290 193-200

Tres LL and Kierszenbaum AL (1983) Viability of rat spermatogenic cells in vitro is facilitated by their coculture with Sertoli cells in serum-free hormone-supplemented medium Proceedings National Academy of Sciences USA $803377-3381$

van der Kooy D and Weiss S (2000) Why stem cells? Science 287 1439-1441
Van Dissel-Emiliani FMF, Grootenhuis AJ, De Jong FH and de Rooij DC (1989) Inhibin reduces spermatogonial numbers in testes of adult mice and Chinese hamsters Endocrinology 125 1899-1903

Van Pelt AMM, Morena AR, Van Dissel-Emiliani FMF, Boitani C, Gaemers IC, de Rooij DG and Stefanini M (1996) Isolation of the synchronised A spermatogonia from adult vitamin A-deficient rat testes Biology of Reproduction 55 439-444

Vogel G (2000) Can old cells learn new tricks? Science 287 1418-1419

*von Schönfeldt V, Krishnamurthy H, Foppiani L and Schlatt S (1999) Magnetic cell sorting as a fast and efficient method of enriching viable spermatogonia from rodent and primate testes Biology of Reproduction 61 582-589

Watt FM and Hogan BL (2000) Out of Eden: stem cells and their niches Science 287 1427-1430

Waxman JH, Ahmed R, Smith D, Wrighley PFM, Gregory W, Shalet S, Crowther D, Rees LH, Besser GM, Malpas JS and Lister TA (1987) Failure to preserve fertility in patients with Hodgkin's disease Cancer Chemotherapy and Pharmacology 19 159-162

Weinbauer GF, Behre HM, Fingscheidt U and Nieschlag E (1991) Human follicle-stimulating hormone exerts a stimulatory effect on spermatogenesis, testicular size, and serum inhibin levels in the gonadotrophin-releasing hormone antagonist-treated nonhuman primate (Macaca fascicularis) Endocrinology 129 1831-1839

Weissman IL (2000) Translating stem and progenitor cell biology to the clinic: barriers and opportunities Science 287 1442-1446

Wreford NG (1995) Theory and practice of stereological techniques applied to the estimation of cell number and nuclear volume in the testis Microscopy Research and Technique 32 423-436

Xie T and Spradling AC (2000) A niche maintaining germ line stem cells in the Drosophila ovary Science 290 328-330

Yoshinaga K, Nishikawa S, Ogawa M, Hayashi S, Kunisada T, Fujimoto T and Nishikawa S (1991) Role of c-kit in mouse spermatogenesis: identification of spermatogonia as a specific site of c-kit expression and function Development 113 689-699

Zhengwei Y, Wreford NG, Schlatt S, Weingbauer GF, Nieschlag E and McLachlan RI (1998a) Acute and specific impairment of spermatogonial development by GnRH antagonist-induced gonadotrophin withdrawal in the adult macque (Macaca fascicularis) Journal of Reproduction and Fertility 112 139-147

Zhengwei Y, Wreford NG, Royce P, De Kretser DM and McLachlan RI (1998b) Stereological evaluation of human spermatogenesis after suppression by testosterone treatment: heterogenous pattern of spermatogenic impairment Journal of Clinical Endocrinology and Metabolism 83 1284-1291 